\title{
ISOLAMENTO DE LINHAGENS DE LEVEDURA DE FOLHAS DE ESPÉCIES ARBÓREAS DA BIODIVERSIDADE DO CERRADO PRODUTORAS DE AMILASES
}

Matheus Henrique Reis da Silva, Odanir Garcia Guerra, Rony Carlos Barcelos Blini

Laboratório de Genética Molecular e de Micro-organismos/ Biotecnologia. Universidade Federal de Mato Grosso do Sul. E-mail: matheush.reis@hotmail.com

\section{RESUMO}

Esse estudo objetivou o isolamento de linhagens de leveduras de filoplano de espécies arbóreas produtoras de amilases, com o intuito de contribuir com a obtenção de amostras com melhor potencial industrial e permitir a constatação do grau de diversidade biológica em relação à microbiota pesquisada. Foram coletadas duas amostras de folha de pequi de cada ponto, sendo quatro amostras em regiões remanescentes de Cerrado e quatro em regiões periféricas, todas no município de Três Lagoas/MS. Foram pesados 1,5 gramas de cada amostra em peso de folha e estas foram cultivadas em $150 \mathrm{~mL}$ de meio mínimo liquido para leveduras (meio S) e suplementado com amido numa concentração final de meio a $0.5 \%$, por $96 \mathrm{~h}$ sob agitação de 150 $\mathrm{rpm}$ a $28^{\circ} \mathrm{C}$. Após o período de incubação cada amostra foi diluída, contada em câmara de Neubauer, plaqueada em triplicata em meio $S$ sólido, para obtenção de aproximadamente 300 colônias por placa e estas foram incubadas em estufa a $28^{\circ} \mathrm{C}$ por um período de $144 \mathrm{~h}$. Após o crescimento, foram observadas colônias morfologicamente diferentes com produção de halos de amilolise os quais foram observados através de coloração do meio com iodo sublimado. Com as analises ficou evidente a presença de linhagens de levedura isoladas do filoplano de pequizeiro que produziram algum tipo de amilase expressada e excretada, in vivo, degradando o amido do meio.

Palavras-chave: enzimas amilolíticas, filoplano, biotecnologia, Cerrado, Pequi (Caryocar brasilienses)

\section{INTRODUÇÃO}

O Cerrado é formado pelo conjunto de formações vegetais de aspectos e fisionomia variáveis, principalmente de árvores baixas e retorcidas que se misturam a um exuberante estrato herbáceo rasteiro. O Cerrado apresenta altos índices de endemismos para as plantas, das 10.000 de suas espécies, 4.400 é endêmico o que representa 1,5\% de toda flora mundial (MEDEIROS, 2011).

As leveduras constituem um grupo de microrganismos integrado no Reino Fungi, domínio Eukarya, caracterizado por um crescimento vegetativo predominantemente unicelular e pela possibilidade de formação de estruturas sexuadas não encerradas em corpos frutíferos. Compreendendo atualmente representantes dos Filos Ascomycota e Basidiomycota (KURTZMAN, 1994) 
As folhas, flores, frutos e caules das plantas constituem um dos substratos mais abundantes e importantes para o desenvolvimento de fungos, em especial, as leveduras. Os nutrientes que estão disponíveis no filoplano (superfície foliar), servem de base para o desenvolvimento de populações de leveduras (TUKEY, 1971).

As amilases estão entre as mais importantes enzimas industriais e são de grande importância na biotecnologia atual (PANDEY et. al., 2000). Vários segmentos industriais utiliza estas enzimas de origem microbiana para converter o amido em unidades fundamentais de glicose. Apesar da produção de amilase ser obtida principalmente a partir de linhagens de fungos filamentosos, várias espécies de leveduras têm sido relatadas com capacidade de degradação do amido, podendo ter alguma aplicação industrial direta ou indireta (GUNDLLAPALLI, 2002).

Esse estudo objetivou o isolamento de linhagens de leveduras de filoplano de espécies arbóreas da biodiversidade do Cerrado produtoras de amilases, com o intuito de contribuir com a obtenção de amostras com melhor potencial industrial e permitir a constatação do grau de diversidade biológica em relação à microbiota pesquisada.

\section{METODOLOGIA}

A espécie arbórea selecionada para realização do estudo foi o Pequi (Caryocar brasilienses), por ser uma árvore facilmente encontrada no município de Três Lagoas e em todo o Cerrado brasileiro.

As amostras de folhas foram coletadas durante o período de outubro de 2012 a janeiro de 2013, perfazendo um total de oito amostras. Foram coletadas duas amostras de cada ponto, as amostras de folhas de pequi foram assepticamente coletadas em sacos plásticos atóxicos estéreis, armazenadas em ambiente com gelo durante as coletas e em seguida transportadas para o laboratório e processadas em até três horas. Este estudo foi realizado em quatro pontos estratégicos do município de Três Lagoas, MS.

\section{Preparação de meios de cultura}

Para o preparo de 1 litro de meio mínimo (meio S) líquido ou sólido para levedura com amido cozido, utilizou-se: 6,7 g de "yeast nitrogen base without amino acids" acrescido de $100 \mathrm{~mL}$ de solução de amido cozido que foi preparado numa solução em concentração de $5 \%$, estando numa concentração final de meio de 0,5\%, $10 \mathrm{~mL}$ de solução de ampicilina e $10 \mathrm{~mL}$ de solução de clorafenicol. Os antibióticos são utilizados para evitar a proliferação de bactérias, outrossim o clorafenicol tem também propriedade inibitória contra fungos filamentosos. Para os meios 
sólidos, adicionou-se $2 \%$ de Agar bacteriológico. Os meios e a solução de amido foram esterilizados separadamente em autoclave a $121^{\circ} \mathrm{C}$ por 20 minutos.

\section{Cultivo e isolamento de linhagens de levedura amilolíticas}

Cada amostra de folha foi cortada assepticamente em pedaços de 2-4 $\mathrm{mm}$ e pesadas em balanças no fluxo laminar para obtenção de 1,5 grama, em seguida foram colocadas em Erlenmeyers de $250 \mathrm{~mL}$ com $150 \mathrm{~mL}$ de meio $\mathrm{S}$ liquido e mantidas em incubadora com agitação mecânica por 96 horas a $28^{\circ} \mathrm{C}$ e $150 \mathrm{rpm}$. Após esse período foram retirados $600 \mu \mathrm{L}$ das amostras da primeira incubação e essa foi utilizada para inocular $150 \mathrm{~mL}$ de meio $\mathrm{S}$ liquido com $0,5 \%$ de amido cozido, em seguida estas amostras foram acomodadas em incubadora com agitação mecânica por 120 horas a $28^{\circ} \mathrm{C}$ e 150 rpm.

\section{Diluição das amostras e contagem das leveduras na Câmera de Neubauer}

Após o período da $2^{2}$ incubação, cada amostra foi diluída em $10^{-1}, 10^{-2}, 10^{-3}, 10^{-4}$ e em seguida foi realizada a contagem na Câmera de Neubauer com objetivo de encontrar uma diluição para conseguir aproximadamente 300 Unidades Formadoras de Colônias (UFC). Para todas as amostras foi usado a diluição $10^{-4}$ alterando apenas o volume que foi semeado nas placas. As amostras foram semeadas em triplicata em meio $S$ sólido, acrescido de amido cozido na concentração final de $0,5 \%$. Estas placas foram mantidas em estufa bacteriológica á 28 으 de temperatura por 144 horas.

\section{Analises qualitativas:}

As colônias de leveduras foram analisadas, qualitativamente, quando à produção de enzimas amilolíticas através da observação visual dos halos de amilolise produzidos após crescimento em meio sólido S, por 168 horas a $28^{\circ} \mathrm{C}$. Para a visualização dos halos de amilolise as placas foram incubadas por 48 horas, a $4{ }^{\circ} \mathrm{C}$. Foram, então, abertas e emborcadas sobre outra placa contendo cristais de iodo sublimado, sendo as colônias expostas ao vapor de iodo o tempo suficiente para que o meio de cultura se tornasse corado. As linhagens de levedura que expressam e excretam amilase apresentam atividade amilolítica que é evidenciada pela formação de halos claros em torno das colônias que promovem a degradação do amido. Assim, é gerado um halo incolor ao redor das linhagens amilolíticos que se sobressai sobre o fundo azul-violeta do meio que ainda contém amido. 


\section{RESULTADOS}

Foram encontrados dez tipos morfológicos diferentes de colônias. No tipo I as colônias exibiam forma circular, superfície lisa, consistência cremosa, elevação convexa e coloração rosada com brilho (Figura 1., item I). No tipo II as colônias apresentavam as mesmas características descritas acima, porém com elevação umbilicada e coloração laranja opaco (Figura 1., item II). No tipo III as colônias apresentaram as mesmas características da colônia I, entretanto com coloração bege brilhante (Figura 1., item III). No tipo IV as colônias apresentaram forma oval, margem regular, elevação plana, consistência seca e coloração bege opaco (Figura 1., item IV). No tipo V as colônias apresentaram as mesmas características da colônia I, porém com elevação umbilicada e coloração branca com brilho (Figura 1., item V). No tipo VI as colônias exibiram forma circular, superfície rugosa, margem irregular, elevação vulcão, consistência butirosa e coloração branca opaca (Figura 1., item VI). No tipo VII as colônias apresentaram os mesmos aspectos do item I, exceto a coloração que foi creme (Figura 1., item VII). No tipo VIII as colônias apresentaram forma ovalada, superfície lisa, consistência buritosa, elevação plana, margens regular e coloração branca opaca (Figura 1., item VIII). No tipo IX as colônias apresentaram forma circular, superfície rugosa, consistência membranosa, elevação umbilicada e coloração lilás opaco (Figura 1., item IX). No tipo $\mathrm{X}$ as colônias apresentaram as mesmas características do tipo I exceto a coloração amarelo claro.

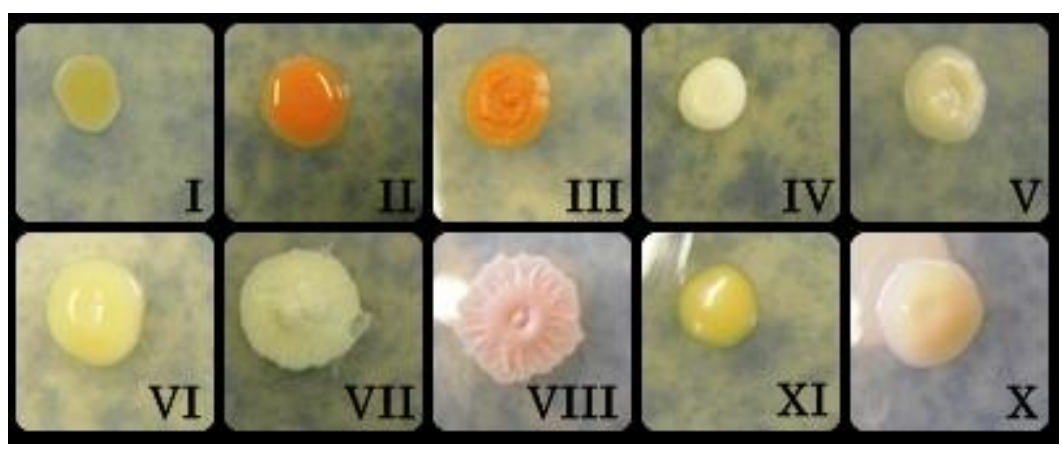

Figura 1. Diversidade das linhagens de levedura isoladas.

Para verificar se houve ou não a produção de amilase, as placas foram observadas e analisadas através da produção de halos amilolíticos. Todas as amostras apresentaram linhagens de leveduras capazes de expressar e excretar in vitro a amilase, com variações bruscas no índice enzimático. A degradação do amido foi eficiente em todos os pontos, demonstrando que as linhagens de levedura metabolizaram de forma eficiente o amido cozido. Na figura 2. é possível ver as colônias com seus halos amilolíticos. 


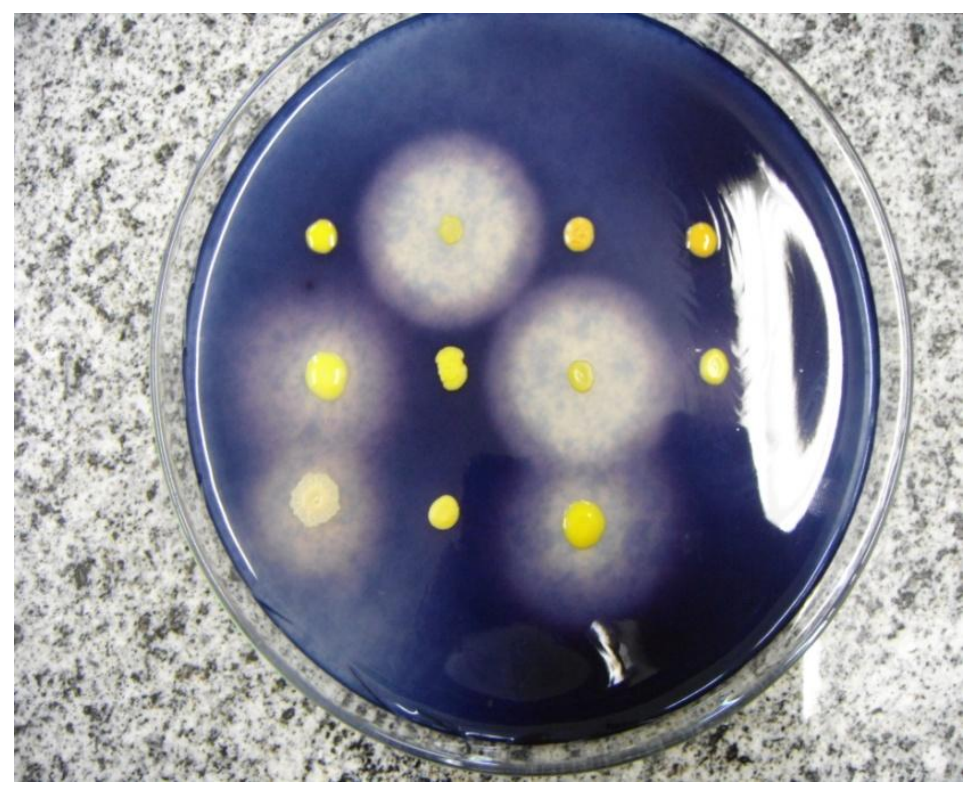

Figura 2. Halos de amilolise com iodo sublimado

Quando as colônias crescem de forma isolada, o tamanho do halo formado pode ser utilizado para determinar o índice enzimático de atividade (IEA). Este índice consiste na relação entre o diâmetro médio do halo descolorido e o diâmetro médio da colônia. IEA: diâmetro médio do halo/diâmetro médio da colônia Desta forma é possível identificar qual a melhor linhagem produtora de enzimas amiloliticas. Muitos estudos utilizam tal procedimento (PEIXOTO, 2006; LANDELL, 2006). Por meio da figura abaixo podemos comparar o IEA das linhagens de levedura.

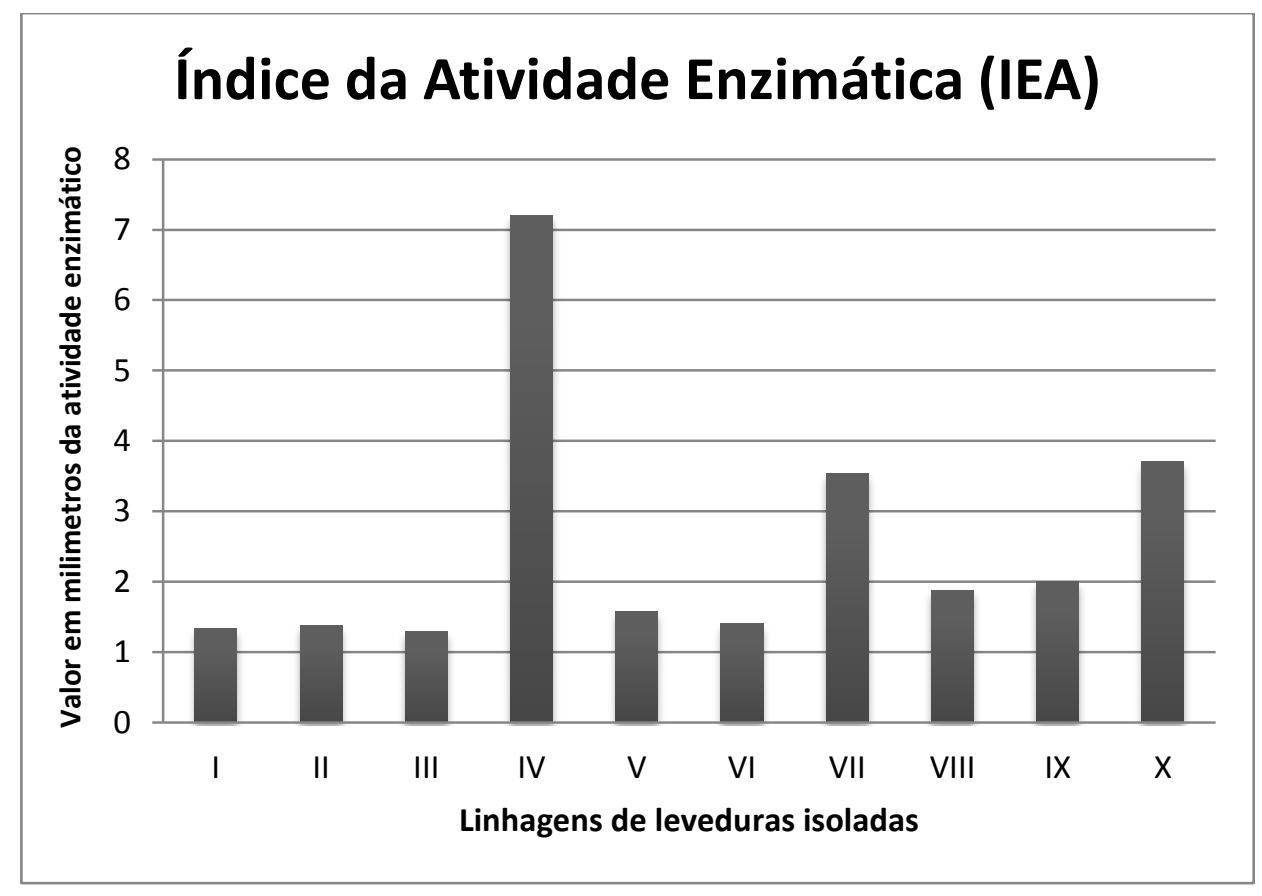

Figura 3. Atividade enzimática das linhagens de levedura isoladas 


\section{DISCUSSÃO}

Peixoto (2006) analisou a produção de enzimas amiloliticas a partir de amostras coletadas do solo, pólen e frutos de diversas regiões do país como: Cerrado,Floresta Amazônica e Mata Atlântica. Dentre as cepas testadas para atividade amilolítica em meio sólido, aquelas coletadas na região da Floresta Amazônica apresentaram maiores atividades em relação às cepas coletadas no Cerrado e Mata Atlântica. A atividade enzimática foi determinada através do (IEA).

Neste trabalho não foi possível identificar o gênero das linhagens de levedura isoladas do filoplano do pequizeiro que degradam o amido cozido, para tal, seriam necessários critérios moleculares e bioquímicos, além da análise das características fisiológicas das linhagens. Entretanto, esta pesquisa servirá de modelo para posterior investigação.

$\mathrm{Na}$ literatura, são encontrados vários trabalhos em relação às amilases fúngicas provenientes de culturas de bolores, principalmente dos gêneros Rhizopus ou Aspergillus (PEIXOTO, 2006). Os trabalhos envolvendo novas linhagens de levedura são reduzidos, entretanto vêm sendo realizados.

A maioria das espécies de leveduras encontradas no filoplano é de afinidade basidiomicética. As leveduras basidiomicéticas são normalmente encontradas em substratos que possuem componentes mais complexos, como folhas e solo, enquanto as com afinidade ascomicética são frequentemente encontradas em substratos ou fontes ricas em açúcares simples, como frutos (Kutzman \& Fell, 1998)

De acordo com Mautone (2008), os gêneros de leveduras basidiomicéticas comumente encontrados associados ao filoplano de plantas são: Cryptococcus, Rhodotorula e Sporobolomyces (Sporidiobolus). Dentre as leveduras ascomicéticas, o gênero mais comum é Candida.

\section{CONCLUSÃO}

Linhagens de levedura do filoplano de Pequi (Caryocar brasiliense) produziram algum tipo de enzima amilolítica que puderam ser expressas e excretas in vitro. As amostras apresentaram atividade enzimática, exibindo possível potencial biotecnológico. Os dados obtidos justificam a continuidade do projeto sobre a produção de enzimas amiloliticas com linhagens de levedura isoladas do Cerrado, com posterior análise e identificação das espécies isoladas. Novos trabalhos nesta área devem ser propostos para o isolamento de novas linhagens de levedura do Cerrado. 


\section{REFERÊNCIAS}

GUNDLLAPALLI, S.B. Different genetic backgrounds influence the secretor expression of the LKAencoded Lipomyces kononenkoae a-amylases in industrial strains of Saccharomyces Cerevisiea strains. Biotechnology Letters, Dordrecht, v.24, p. 651-656, 2002. http://dx.doi.org/10.1023/A:1015003610472

KURTZMAN, C. P. Molecular taxonomy of the yeasts. Yeast. 10: 1727-1740. 1994.

KURTZMAN, C.P.; FELL, J. The Yeast, a taxonomic study. $4^{\text {rd }}$ ed. Amsterdam: Elsevier Science Publishers, p. 1088, 1998. http://dx.doi.org/10.1002/yea.320101306

LANDELL, M.F. Biodiversity of associated to bromeliads in Itapuã Park, Viamão/RS. Biociências, Porto Alegre, v. 14, p. 144-149, 2006.

MAUTONE, J.N. Biodiversidade e potencial biotecnológico de leveduras e fungos semelhantes a leveduras isoladas de folhas de figueiras do Parque de Itapuã-Viamão/RS. 2008. Dissertação (mestrado) - Programa de Pós-Graduação em Microbiologia Agrícola e do Ambiente, Faculdade de Agronomia, Universidade Federal do Rio Grande do Sul, Porto Alegre, p. 23, 2008.

MEDEIROS, J. D. Guia de campo: vegetação do Cerrado 500 espécies. Brasília: MMA/SBF, 2011.

PANDEY, A.; NIGAM, P.; SOCCOL, C. R.; SOCCOL, V. T.; SINGH, D.; MOHAN, R. Advances in microbial amylases. Biotechnol. Appl. Biochem., v. 31, n. 2, p. 135-152, 2000. http://dx.doi.org/10.1042/BA19990073

PEIXOTO, A. B. Estudo da produção de enzimas e gomas de leveduras selvagens coletadas em diversas regiões do Brasil. 2006. 84 f. Dissertação (Mestrado em Engenharia de Alimentos) Faculdade de Engenharia de Alimentos, Universidade Estadual de Campinas, Campinas. 2006.

TUKEY, H.B.Jr. Leaching of substances from plants. In: Preece, T.F.; Dickinson, C.H. (eds). Ecology of Leaf Surface Microorganisms. London: Academic Press, 1971. 